\title{
DA PALAVRA DO OUTRO À PALAVRA PRÓPRIA: CONVITE À AUTORIA DE PROFESSORAS
}

\author{
Maria Francisca Mendes ${ }^{\mathrm{i}}$
}

\begin{abstract}
Resumo: Afirmar o caráter político da educação é compreendê-la em estreita relação com a sociedade na medida em que é a expressão de suas crenças, valores e esperanças sociais. Escrever e socializar saberes produzidos na prática cotidiana significa legitimar professoras, suas práticas e autorias. Para isso, é fundamental estabelecer uma postura dialógica na qual a palavra da professora seja retirada do anonimato e tenha reconhecidos não só sua palavra, mas os sentidos que imprime ao campo pedagógico. A documentação narrativa, sublinhada por Suarez (2013), constitui o saber produzido acerca das experiências cotidianas que só as professoras que habitam esse mundo educativo podem dizer/escrever.
\end{abstract}

Palavras-chave: Escritas de professoras; Documentação narrativa; Professora pesquisadora; Cotidiano educativo.

\section{FROM THE VOICE OF ANOTHER TO THE SELF VOICE: AN INVITATION TO TEACHERS AUTHORING}

\begin{abstract}
To assert the education political character is understand it in a narrow relationship with the society, as far as expresses its beliefs, values and social hopes. To write and socialize knowing daily produced means legitimize teachers, theirs practices and authorings. In this regard, is essential to set dialogical attitude up, in wichy the spech's teacher stays aside from anonymity and be reconized, as much as the ideias that they provide to the educational field. The oral documentation detached by Suarez (2013) compounds the knowing daily produced, that only teachers that inhabits this educational world can say/write.
\end{abstract}

Keywords: Teachers' writings; Narrative documentation; Teacher-researcher; Educative routine.

O leão não sabia escrever.

Mas isso não o atrapalhava, pois ele sabia rugir e mostrar os dentes.

E o leão não precisava de mais nada.

Um dia, ele encontrou uma leoa. A leoa estava lendo um livro e era muito bonita.

O leão foi se aproximando e quis beijá-la.

Mas de repente ele parou e pensou melhor. Uma leoa que lê é uma dama. E para uma dama a gente escreve cartas, antes de beijá-la. O leão tinha aprendido isso com um missionário que ele tinha devorado. Mas o leão não sabia escrever.

Então, ele procurou o macaco e disse:

- Por favor, escreva uma carta para a leoa. 
No dia seguinte o leão foi levar a carta ao correio. Mas ele queria saber o que o macaco tinha escrito. Então o leão voltou e fez o macaco ler. E o macaco leu:

"Querida amiga, quer subir nas árvores comigo? Também tenho bananas para lhe oferecer. São deliciosas! Saudações, Leão."

- Nada disso! - rugiu o leão. - Eu jamais escreveria uma coisa dessas!

E o leão rasgou a carta.

Então ele foi até o rio e pediu para o hipopótamo escrever outra carta.

No dia seguinte o leão foi levar a carta ao correio.

Mas ele queria saber o que o hipopótamo tinha escrito.

Então ele voltou e o hipopótamo leu:

"Querida amiga, quer nadar comigo no rio e mergulhar para catar algas? São uma delícia! Saudações, Leão."

- Nãããããoo! - rugiu o leão. - Eu jamais escreveria uma coisa dessas!

(BALTSCHEIT, 2010)

Uma das experiências atuais que vivo como professora é a orientação da escrita de alunos em conclusão de cursos ${ }^{\mathrm{ii}}$. Supõe-se que esta seria uma etapa em que os educandos já estivessem mais familiarizados com o ato da escrita e, consequentemente, com facilidade maior em exercê-lo. Ledo engano. Persiste o desafio de se colocar diante de uma folha em branco e sobre ela traçar algumas linhas. E ainda causa sofrimento. Duas perguntas iniciais são necessárias ao temeroso escritor para que possa perceber o sentido da escrita: "Sobre o que você quer escrever?" e "Por que esse tema lhe é importante?".

O desejo maior é fazer com que as professoras compreendam que o ato de narrar sua própria história, mais do que contar uma história sobre si, é um ato de conhecimento (PÉREZ, 2002, p. 55). Mesmo que tenhamos prazer ao nos depararmos com nossas escritas prontas, o percurso de elaboração reconhecemos, por vezes, doloroso, difícil, desafiador.

Talvez o caminho de construção da escrita possa contemplar um outro sentido se pensarmos o que fazer com as palavras que nos povoam, imersas que estão nas experiências vividas. Você, leitora deste texto, gosta de escrever? Acha a escrita um movimento prazeroso? Costuma registrar as experiências cotidianas através de textos? Procura manter um portfólio das histórias que vive com as crianças e jovens com os quais interage diariamente? Pois então vamos conversar de autoria. Compreender esse sentido requer compreender-nos: quem somos?

Somos professoras ${ }^{\mathrm{iii}}$ em permanente diálogo com o mundo, comprometidas com um fazer pedagógico que traga visibilidade à nossa prática. Nos encontros - formais ou informais - com os pares, falamos e ouvimos, conversamos e discutimos. Somos interlocutoras umas 
das outras: temos a intenção de ensinar e de aprender porque acreditamos que o amanhã não é inexorável (FREIRE; GUIMARÃES, 2011). E, por isso, estamos fazendo nosso amanhã a partir da feitura do hoje. Refletimos sobre ações enquanto elaboramos novas escolhas. Não buscamos o saber acadêmico hermético, sem diálogo, ressonância ou réplica. Ao rememorar, criamos um conhecimento novo - fazer memória é um pouco recriar o que foi feito (Ibid., p. 33). Através do diálogo, pensamos as consequências de um ato e revemos ações futuras entendendo a linguagem como constituidora do sujeito histórico e social.

A vida é dialógica por natureza. Vivemos fazendo perguntas, prestando atenção, respondendo, criando novas indagações num movimento em que está presente todo o nosso ser, e que vai se constituindo a partir da multiplicidade de vozes com as quais interagimos. Pensar a linguagem na perspectiva dialógica implica concebê-la como acontecimento social, fruto da comunicação verbal de um ou mais enunciados que ocorre entre sujeitos. Por essa razão, trago para as reflexões Freire e Bakhtin, teóricos do diálogo. Ambos compreendem o homem como sujeito histórico e de relações com tempo e espaço definíveis, mas jamais delimitados: as fronteiras são limites a serem ultrapassados pelas transformações que a ação humana responsável é capaz de realizar (GERALDI, 2012, p. 10).

Comumente vemos nas pesquisas acadêmicas as palavras das professoras serem incorporadas como referência para aquilo que pesquisadores querem dizer. Esse modo de apropriação recusa o sentido da autoria. As professoras têm sua palavra habilitada, mas não seus saberes e conhecimentos. Cabe, portanto, estabelecer uma postura dialógica na qual a palavra da professora seja retirada do anonimato e tenha reconhecidos não só sua palavra, mas os sentidos que imprime ao campo pedagógico.

O saber produzido acerca das experiências cotidianas, que só as professoras que habitam esse mundo educativo podem dizer/escrever, constituem o que Suarez (2013) denomina de “documentação narrativa". As narrativas são reconstruções dinâmicas das experiências de professoras implicadas com seus fazeresaberes ${ }^{i v}$. Através de um processo reflexivo vão significando o que vivem, estruturando suas práticas e se constituindo através destas (SUAREZ, 2007).

A documentação narrativa não se restringe à escrita de atas, memoriais, registros reflexivos. Suarez (2013) destaca quatro dimensões presentes nesta escolha investigativa na relação com a docente narradora: a escrita, a leitura, os comentários e as conversas. Nesse processo coletivo, aprofundam-se a escrita e a reescrita, intensificam-se as leituras, a escrita 
das leituras comentadas e as conversas que se estabelecem a partir dos questionamentos suscitados pela prática e pela escrita. Suarez entende a documentação narrativa como uma forma de alfabetização docente: aprende-se a dizer a própria palavra. Alfabetização? Será a vida um eterno recomeço?

$\mathrm{Na}$ busca por entender os fenômenos sociais e educativos, as professoras precisam apropriar-se de sua dimensão pesquisadora. Até então rotuladas de leigas, assumem a condição de teóricas cujas elaborações acerca do vivido irão nortear estudos e conhecimentos produzidos e constituem-se professoraspesquisadoras. Não há pesquisa sem reflexão, como já afirmava Freire (1999), ao enfatizar a indissociabilidade entre pesquisa e ensino onde ambos se incorporam.

\section{Da professorapesquisadora ou a professora e sua dimensão pesquisadora: o direito de dizer a própria palavra}

Faz parte do estatuto da professorapesquisadora lutar pelo direito de ser professorapesquisadora. Na relação com o outro, tanto aprendo quanto ensino. Nem sempre pensei assim: sabia-me apenas professora. Fui ensinada de que uma profissional na escola é professora e na academia é pesquisadora, condição assumida apenas com o mestrado. Lembro-me da necessidade permanente de clarificar ambos os papéis, até porque os considerava diferenciados: quando falava a professora? Em quais momentos seria a vez da pesquisadora se colocar?

A compreensão do encontro entre as duas dimensões só foi ocorrer no doutorado. Da inquietude surgida por esse desconhecimento, trilhei um caminho na defesa de minha constituição como professorapesquisadora desde o início da docência, quando assumi a constância do olhar problematizador sobre a prática. Freire foi, sem dúvida, um grande aliado. Descobri que a condição de pesquisadora não era uma qualidade que eu deveria agregar à docência porque a pesquisa, a indagação e a busca são aspectos inerentes à prática. Importa que, em sua formação permanente, o professor se perceba e se assuma, porque professor, como pesquisador (FREIRE, 1999, p. 20).

Considero-me uma professorapesquisadora pelo fato de debruçar-me sobre minha prática cotidiana a partir do instante em que assumi a docência. Professora alfabetizadora, não me furtei a seguir os receituários de uma cartilha e seu manual. Entretanto, logo um olhar 
crítico se instaurou desnaturalizando diretrizes. As tantas indagações levaram-me a inúmeros cursos, mestrado e doutorado. Mas não foram estas as instâncias que me tornaram um sujeito reflexivo. Entendo que a pesquisa sempre esteve presente nas ações pedagógicas assumidas diante dos impasses entre fazeres e saberes evidenciando a necessária articulação práticateoriaprática.

Enquanto as crianças tentavam desembaralhar um emaranhado de letras lançadas sobre um papel, eu aprendia a ler as crianças, seus desejos e interesses, dúvidas e temores. E me inquietava diante de cada atitude assumida e de suas respostas. Aprendemos, eu e as crianças, a perguntar. A contestação - ou uma certa rebeldia, no sentido mais humano da expressão (FREIRE, 2001b, p. 98) - levou-me à busca incessante, à recriação, à inovação. São estas algumas das razões que fazem com que eu me considere uma professorapesquisadora. Os estudos trouxeram outras possibilidades de conhecer e tentar definir as inquietudes de uma professora que busca manter um olhar de estranhamento acerca das experiências docentes.

São muitos os que compõem o universo de um profissional reflexivo, mas poucos aqueles que se adéquam à classificação de pesquisador, detentor de um saber supremo legitimado pela academia. Cabe ressaltar que este é um saber direcionado a uma parcela mínima dos que buscam estudar seus fazeresaberes. Novamente a experiência é minha aliada porque vivi o desafio de trilhar árduos caminhos até conquistar um espaço acadêmico.

A concepção de professorapesquisadora redimensiona toda a relação fazersaberfazer. Parte-se do princípio de que a prática é o eixo propulsor da formação. A ela se alia a teoria que permite a observação mais minuciosa de cada acontecimento. O questionamento assume a centralidade de todo esse processo. Estranhamento, inquietação, criticidade são atitudes que colocam a professora em uma postura reflexiva de um permanente diálogo práticateoriaprática ressignificando os problemas concretos vivenciados na realidade cotidiana.

As experiências trazidas para o contexto acadêmico promovem discussões que levam ao aprofundamento teórico e, consequentemente, ao desvelar de novas proposições. A academia se transfigura, assim, em um autêntico ambiente educativo no entretecer de histórias construídas no espaço cotidiano da sala de aula e teorizadas a partir do diálogo com o outro. Esse é, sem dúvida, um percurso que não se faz sozinho. Ainda que as experiências sejam únicas, singulares, as reflexões e as trocas que elas possibilitam são enriquecidas por diversos 
outros olhares que ampliam os referenciais práticosteóricospráticos e fortalecem a cada um e a todos no enfrentamento dos impasses.

Percebi que boa parte deste espaço seletivo (acadêmico), no qual me incluo atualmente, não traz as marcas de experiências vividas no cotidiano de uma prática que pode ser tão dolorosa quanto instigante. Muitos não têm uma prática consolidada, mas sim um pensar teórico sobre o que a imaginam ser; e passam a se fundamentar hipoteticamente sobre uma prática idealizada. Defendo a prática como relevante porque dela advêm as interrogações que nos impulsionam aos estudos.

O olhar investigativo sobre o cotidiano é constituído pelos conhecimentos que se tem (ESTEBAN; ZACCUR, 2002, p. 21) frutos das inquietudes que desconfortam, acrescentaria. Tentamos compreender a complexidade da vida de ser uma professora. Escolhemos ser e estamos sendo. E procuramos, com nossas escritas, exercitar a descoberta na busca por aprendizagens "alternativas". Ouvimos o outro e perguntamos, observamos a intensidade de sua fala, escutamos seu silêncio, nos calamos com sua angústia, procuramos compreender seus sentidos, nos abrimos à cumplicidade de um diálogo que, por vezes, nos surpreende.

Enquanto especialistas falam sobre nós, impondo mudanças que devem ser feitas em uma realidade a qual desconhecem por não estarem mergulhados nela, procuramos falar entre nós das coisas que nos incomodam, observadas em um espaço do qual nos sentimos construtoras. A cada dia, abrimos as janelas, modificamos os móveis de lugar, lavamos as cortinas, buscamos pensar nossas necessidades na companhia do outro, seja um adulto, seja uma criança.

Por que autorizo o outro a falar de questões que são minhas? Se fui eu quem as viveu, por que delegar ao outro essa narrativa e aceitar silenciar minha voz? Como se atribui legitimidade a um discurso? Por que o outro pode falar de mim e eu não posso? Retorno às indagações presentes em minha dissertação e no cerne desse embate está a desvinculação entre teoria e prática. Os pesquisadores e seus discursos teóricos falam de uma prática que não é aquela vivida pela professora. Esta, por sua vez, quando busca investir na formação, não se reconhece nas leituras acadêmicas. Cabe-nos compreender que essas contradições por vezes estarão presentes em maior ou menor grau no contexto educativo.

Há os que acatam os discursos (im)postos, há os que desconsideram e continuam fazendo o que acreditam e há aqueles que, dependendo de uma conjuntura favorável, se aproveitam das brechas e assumem a mudança, porque são produtores de conhecimento, 
independente do que dizem os discursos autoritários. Revendo meu percurso ao longo de anos no magistério posso considerar já ter assumido todas essas posturas. Contudo, a última proposição tem referendado a condição de professorapesquisadora.

Manter um processo de investigação permanente sobre a prática cotidiana a partir do diálogo com a documentação narrativa contribui para uma outra política de conhecimento na área pedagógica, uma forma alternativa em que se possa pensar as relações de poder e saber no campo educativo. A documentação narrativa trata, portanto, da necessidade de organizar, reconceitualizar, redefinir, revitalizar a tradição crítica a partir da recuperação, reconstituição e publicação de saberes em torno das experiências das práticas pedagógicas a partir dos relatos docentes (SUAREZ, 2013).

\section{A dialogicidade entre sujeitos inacabados}

Construir sua própria história, refletir por escrito a partir das ações cotidianas, revelar medos, entre tantos outros sentimentos, pode constituir a possibilidade de se assumir a palavra e conquistar autoria. Soligo e Prado (2005) alertam para "os perigos" da escrita: ela nos faz pensar, organiza as ideias, socializa pensamentos, eterniza escolhas. No percurso das escrituras vamos descobrindo que escrever exige a todo instante um deslocamento do autor, indo de sua posição de escritor para a de leitor do próprio texto. (...) Aquele que escreve tem de ser, quase ao mesmo tempo, autor, leitor e revisor (p. 35).

Urgente se faz assumirmos autoria - e lutar por esse direito - não somente na prática cotidiana nas escolas, mas em todos os espaços coletivos de formação. Acreditamos que ato pedagógico e ato político são instâncias indissociáveis. Não há educação neutra, nem pedagogia única. Cada pedagogia está a serviço de determinados interesses, dependendo da classe à qual ela responda. A educação não se restringe ao espaço pedagógico da sala de aula: por ser libertadora, põe abaixo qualquer possibilidade de cerceamento, seja através das paredes da sala ou dos muros da exclusão. A educação defendida por Freire é conscientizadora de vida e de mundo.

Os saberes acadêmicos são alimentados pelas questões que emergem da prática e as indagações construídas no fazer diário. Não se trata de desconsiderar importância e necessidade de um aprofundamento teórico porque este nos traz respostas e novas dúvidas; 
entretanto, os fazeres cotidianos nos constituem a partir das experiências que vivemos em espaçostempos contextualizados historicamente. Assim, os saberes acadêmicos auxiliam a prática gerando novas perguntas constitutivas de um processo ininterrupto pelo conhecer, aprender, descobrir, indagar, fazersaber.

A pedagogia dialógica e dialética comporta diálogo, mas, principalmente, conflito, suspeita, indagação, estranhamento, rebeldia. O compromisso do sujeito consigo e com o outro é o compromisso de estar no mundo com o mundo, onde a ação e a reflexão constituemse pilares desse comprometimento: somente este ser é já em si um compromisso (FREIRE, 1981, p. 17). O homem é um ser da práxis; e isso se reflete nas ações mediadas pelas reflexões que cada escolha exige.

Reconhecer-se inacabado é condição básica para assumir uma permanente educação na busca incessante de ser mais: esta é a raiz da educação (FREIRE, 1981). O homem é sujeito da própria educação, sendo assim, ninguém educa ninguém. Essa é uma busca que não se faz sozinho, preciso do outro, de outras consciências; preciso estar com. Todos sabemos algo de alguma coisa; não há ignorância absoluta. O desafio para nós, educadoras, é o de reconhecer e legitimar esse conhecimento como um saber que se faz de superações.

A consciência do inacabamento nos encoraja a uma permanente busca, fazendo-se e refazendo-se na história, e reconhecendo a história do outro. Nessa concepção, seria contraditório o ser humano não se reconhecer um ser de busca: toda procura gera a esperança de achar e ninguém é esperançoso por teimosia (FREIRE, 2000, p. 120). Nas experiências que vivo, mediadas pelas relações que estabeleço com o mundo, é a curiosidade que me leva a querer saber, a indagar, a questionar, a estranhar. Somos seres da pergunta; conhecemos a partir das indagações. Por esse motivo valorizamos uma educação crítica da curiosidade (FREIRE, 1999). Assim como a busca, a educação é permanente.

Para refletir teoricamente sobre a minha prática, não preciso distanciar-me das experiências que vivo: o que torna teórico um contexto não é seu espaço e sim a postura da mente (FREIRE, 2001a, p. 78). Assumir uma atitude epistemologicamente curiosa implica construir um olhar atento aos detalhes, aos não ditos, às singularidades, às invisibilidades. Nesse percurso vamos desafiando nossa própria curiosidade por vezes ingênua no sentido de torná-la crítica, desocultando os tantos escondidos.

O homem não está apenas no mundo, mas com o mundo. A cognoscência faz parte desse estar. Decorre disso a importância, como educadoras, de estimularmos nossa 
consciência reflexiva e a das demais aprendentes que conosco interagem, propiciando novos olhares para e com a realidade. Compreender a própria realidade leva o homem a refletir, levantar hipóteses e construir soluções para as questões que enfrenta, no sentido de ressignificá-las. E é com a cultura que o homem percorre esse caminhar, criando e recriando passos.

Um dos traços marcantes da educação é a recriação, a transformação da realidade e não a adaptação: o homem se identifica com sua própria ação, objetiva o tempo, temporalizase, faz-se homem-história (FREIRE, 1981, p. 31). Uma educação fundada na adaptação retira do homem a possibilidade de autoria, o direito à criação, o poder de fazer escolhas, a opção de afirmar-se sujeito livre e consciente de seu compromisso consigo mesmo e com o outro. É essencial que esse homem siga fazendo história pela sua própria atividade criadora (Ibid., p. $33)$.

Ao entender que todo amanhã se cria num ontem, através de um hoje (Ibid., p. 33), partimos em busca de nossas histórias, do que já fomos e de quem nos tornamos, para finalmente decidirmos o que seremos, ou clarearmos o que estamos sendo. Ainda que contraditórias, mudança e estabilidade estão intrinsecamente relacionadas e surgem da ação do homem no mundo. Ao criar seu mundo histórico-cultural, o homem, um ser de práxis, se vê condicionado por toda essa mudança impressa na própria produção.

A estrutura social é produto das relações do homem; transformá-la também está a cargo desse homem. Daí sua posição jamais poder ser neutra. O homem é um ser de escolhas, e cada opção assumida pode estar a serviço da desumanização ou humanização, da permanência ou mudança de seus caminhos. À opção assumida, aliam-se técnicas e métodos que fundamentam a escolha feita. Acreditamos que nossa opção seja pela mudança.

\section{Os múltiplos sentidos inscritos na escrita}

Na trajetória de uma professora, dois saberes precisam se tornar presentes: ler e escrever. A leitura e a escrita possibilitam ampliar conhecimentos, promover aprendizagens e expressar ideias e sentimentos. Através da leitura nos deparamos com o universo letrado; enquanto que a escrita nos eleva à condição de autores. Essa dupla apropriação faz com que nos sintamos pertencentes a um mundo repleto de sentidos, compartilhando experiências que, 
quando reveladas, deixam de ser individuais para se transformarem em coletivas. Esse é um encontro que se dá conosco e com o outro. Leitura e escrita são condições de autoria: escrevemos porque lemos!

Quando escrevo, sinto-me tateando na obscura trilha em que me lanço, para conhecer minhas maneiras de fazer e de narrar práticas comuns de homens ordinários. Por certo, a empreitada exige uma maneira de caminhar. Pegadas deixadas pelo caminho são pistas para que eu seja encontrada - e lida; não necessariamente compreendida. Como professoraspesquisadoras estamos à caça nessa estrada: entendemos que o cotidiano se inventa com mil maneiras de caça não autorizada (CERTEAU, 2011, p. 38 - grifos do autor) a partir da astúcia das praticantes. Caçamos os múltiplos sentidos inscritos nas palavras e nas práticas cotidianas.

O espaço da escrita é o lugar da prática - onde se operam as práticas. A própria escrita é uma prática. Então, quais são as nossas maneiras de fazer? Quais as formas que encontramos - as praticantes - para compreender o cotidiano e nossa inserção nesse contexto? Para Certeau (2011), o fazer é uma arte; e se é arte, pressupõe elaboração. Nesse sentido, a prática é uma arte do fazer, uma forma de se inscrever no mundo; não há, pois, sentido em deslocá-la da escrita do mundo.

Pesquisar o cotidiano nos leva a considerar a essencialidade da não separação entre $o$ conteúdo-sentido de um determinado ato-atividade e a realidade histórica de seu existir, sua vivência realmente irrepetível (BAKHTIN, 2010, p. 42). A totalidade faz deste um ato verdadeiro, vivo e pleno. A unidade do ato caminha em duas direções. O mundo da vida, no qual o homem se situa a partir de sua experiência singular, não pode prescindir do mundo da cultura. E é justamente a singularidade da existência que pode transformar esses dois mundos em unidade singular.

Professoras se inscrevem quando escrevem memoriais, atas, registros reflexivos, textos teóricos e quando discutem incômodos em reuniões através de seus depoimentos. Todos esses documentos são fontes de pesquisa para uma escrita contextualizada, produto de minha interação com o outro e com as questões que provocaram esse percurso de autoria. Sem dúvida que o texto resultante desta relação está atravessado de outros textos com os quais dialoga. Nesse sentido, minha palavra comporta vozes alheias com as quais passo a dialogar imprimindo acentos, objeções, réplicas. Para além de um mero instrumento de comunicação, a palavra constitui a própria experiência do falante. 
A relação que passo a estabelecer com essa multiplicidade de vozes exige assumir o olhar exotópico daquela que faz parte do evento, mas, ao mesmo tempo, mantem um distanciamento no sentido de construir o acabamento estético que só acontece quando do encontro com o outro, do encontro de consciências. Colocar-me no lugar desse outro e de suas enunciações, a partir de meu excedente de visão (BAKHTIN, 2000), faz com que eu possa dar um acabamento para as tantas reflexões, buscando respostas e construindo novas indagações.

Acima de tudo está a compreensão de que esse sujeito não é individualmente potente: ele se constitui no seu espaço e a consciência que constrói em sua história é aquela que resulta de suas interações com a alteridade (GERALDI, 2012, p. 10). O princípio da alteridade sublinha esse entendimento: minha constituição depende da consciência do outro na medida em que a interação social é constituída pelo encontro de consciências.

Histórias são escritas cotidianamente por homens ordinários (CERTEAU, 2011). E são as histórias cotidianas, de homens ordinários, que devemos buscar publicizar. A escrita de nossa prática só tem sentido se pudermos refletir sobre ela. Escritas e depoimentos constituem um espaço singular da narrativa.

Por que defendo tanto que cada professora assuma seu direito a ter a própria palavra reconhecida? Porque sou uma passante. Tenho tomado por empréstimo propriedades do outro - as palavras - e procuro fazer desses bens as soluções de histórias mudas (CERTEAU, 2011, p. 48). Assumir a palavra, enquanto ato, significa responsabilizar-se pelo outro através de seu dizer único, irrepetível e insubstituível (PONZIO, 2010, p. 32). Todo enunciado requer uma compreensão responsiva, ativa, contendo assim o germe da resposta.

A compreensão responsiva permite a apreensão do tema. Na réplica que fazemos a um enunciado - contrapalavras - vamos orientando nossas palavras na direção do que está sendo discutido. Trata-se de um encontro concreto, estruturado na relação de não indiferença com o outro real; uma relação responsável, que exige responsividade na interação com a palavra outra, procurando ressaltar singularidades. Penso que para a palavra e, por conseguinte, para o homem, nada é mais terrível do que a irresponsividade (a falta de resposta) (BAKHTIN, 2000, p. 356 - grifo do autor).

\section{Educação como ato político: de escrever e inscrever-se nas práticas cotidianas}


A intenção destas reflexões aqui inscritas é a de valorizar o trabalho com o cotidiano docente despindo-se de (pré)conceitos, pois o cotidiano desafia o tempo todo - a nós e a nossas certezas. Leitura e escrita podem ser desenvolvidas dentro de uma postura de se deixar surpreender, afetar, tocar, sensibilizar, enfim, dar as palavras (LARROSA, 2003).

Há o tempo do vivido e o tempo do narrado. Entre o vivido e o narrado há um distanciamento. Ao narrar, realizo uma prática diferenciada do que vivi - fica o que significa. Assim, não preciso me preocupar com o tempo quando rememoro uma experiência. O que escolho narrar não é somente o vivido, mas a experiência do vivido. As diferentes significações tecem uma rede de significados partilhados nos encontros e desencontros.

Narrar a experiência é se trazer para esse processo em que o narrador é também protagonista. Há diferença entre narrativa e relato. A preocupação do relato é com a descrição, o registro de acontecimentos. No relato, trago o acontecido. O relato se transforma em narrativa quando me coloco nessa escrita, porque experiência única, porque só minha. Através da narrativa me reinvento no acontecido. A narrativa é uma experiência; e só a experiência pode ser narrada. A narração ecoa no sujeito que narra e no ouvinte; pressupõe uma reflexão do narrador e de quem o ouve. Está ligada diretamente à nossa subjetividade, ao nosso íntimo, à nossa forma de serestar no mundo.

Ao escrevermos procuramos relacionar a construção de um texto com a problematização das diferentes vozes, suas contradições e dilemas que constituem os olhares acerca do vivido. Defendo que quem escreve deve ser respeitada nessa autoria por entender que não é o conteúdo da obrigação escrita que me obriga, mas a minha assinatura colocada no final, o fato de eu ter, uma vez, reconhecido e subscrito tal obrigação (BAKHTIN, 2010, p. 18).

Aprendi com Bakhtin (1998) de que, quando me expresso, não trago um pensamento inédito porque a palavra que falo já foi uma palavra falada antes. Mas encontra-se povoada pelo meu acento, a minha história, as minhas marcas. E nessa feitura, reconheço a presença do outro. Uma palavra, ao ser pronunciada, carrega o tom emocional volitivo da expressão do pensamento pelo sujeito. A entonação reflete a forma como percebo a experiência vivida, o sentido inscrito em um determinado momento.

Dentre todos os signos, a palavra é o fenômeno ideológico por excelência. A palavra, em seu estado puro, é neutra. Quando inserida no processo de comunicação, ou seja, dentro de uma enunciação, ela perde a neutralidade e passa a incorporar uma função ideológica. Dessa 
forma, a palavra é constituída por uma infinidade de fios ideológicos e se encontra marcada pelo horizonte social de uma época e de um determinado grupo social. Assim, os signos ideológicos são construídos nas interações sociais a partir dos embates entre os sujeitos.

São as particularidades e não as generalizações presentes nas narrativas, sejam escritas ou orais, que nos convidam ao diálogo, impelem a retrucar, debater, discordar, complementar. São as singularidades que nos capturam, são os detalhes e as emoções que trazem a vida vivida e a vida sentida e encontram eco em nós. Esse olhar essencialmente humano constrói a mediação entre a vida concreta e investigação. A ética está diretamente relacionada às escolhas feitas e às responsabilidades assumidas. Para haver ética precisa haver escolha. E uma das escolhas, sem dúvida, é a de caminhar no sentido de superar as injustiças que desumanizam.

Em seu fazer diário, geralmente as professoras são tomadas como objetos de pesquisas pelos pesquisadores acadêmicos, também professores, responsáveis em formular referenciais teóricos a serem seguidos cabendo aos primeiros a opção de consumir passivamente o produto destes estudos. Dessa forma, nega-se a esta professora a possibilidade da parceria e, acima de tudo, da autoria de um conhecimento que pode ser um aliado seu na construção de uma educação mais justa e coerente para todos os envolvidos. Pensar mudanças na educação é pensar essas mudanças com as professoras e não sobre elas.

Mesmo com todo o receio de não sermos compreendidas, sequer conseguirmos falar, precisamos seguir adiante teorizando o cotidiano e publicizando as experiências. Devemos tentar reverter a forma de entendimento acerca da pesquisa científica trazendo para a discussão a dicotomia presente ainda hoje entre o pensar e o fazer: a uns cabe o pensar, porque detém a teoria que produz conhecimentos; a outros resta o fazer, enquanto mão-deobra mecânica e alienada.

Não é fácil conviver com a frustração de constatar que pouco - ou quase nada - pode ser alterado no cotidiano docente. Atitudes idealistas e solitárias não têm força para combater o que está posto. Reconhecer limites e possibilidades dos fazeresaberes pode funcionar como um primeiro passo de uma jornada que não se trilha sozinho.

A narrativa das experiências, aliada à reflexão da prática pedagógica, acentua o caráter reflexivo da escrita como instrumento valioso na formação: a palavra é o fenômeno ideológico por excelência. (...) é o modo mais puro e sensível de relação social (BAKHTIN, 1981, p. 36 - grifos do autor). Além disso, o ato de revelar-se - mas também camuflar-se - 
nas linhas do papel assume uma dimensão política quando essas experiências se tornam públicas: valoriza-se uma escrita que, até pouco tempo atrás, era privilégio quase que exclusivo da academia e seus pesquisadores.

As memórias que compõem nossa história podem ser recuperadas, narradas e escritas. Podemos fazê-lo. Através da linguagem, articulamos memórias individuais e coletivas possibilitando refletir sobre escolhas assumidas e compreender percursos trilhados imprimindo novos sentidos a essas experiências. Escrever tanto pode ser um processo árduo, um processo criativo ou mesmo uma necessidade. Penso que o ato de escrever e inscrever-se nas linhas do papel simboliza um desafio maior ainda; não são muitos os que se arriscam por esses caminhos.

Como acredito que educação exige reinvenção (FREIRE, 2001a), sigo recriando meus passos nos lugares, nas relações de encontro com o outro e na tessitura de narrativas que engendram novas maneiras de caminhar. Que tal caminharmos juntas?

\section{REFERÊNCIAS}

BAKHTIN, Mikhail. Para uma filosofia do ato responsável. São Carlos: Pedro \& João Editores, 2010.

. Estética da criação verbal. São Paulo: Martins Fontes, 2000.

. Questões de literatura e de estética. São Paulo: Hucitec, 1998.

. Marxismo e filosofia da linguagem. São Paulo: Hucitec, 1981.

BALTSCHEIT, Martin. A história do leão que não sabia escrever. São Paulo: Editora VMF Martins Fontes, 2010.

CERTEAU, Michel de. A invenção do cotidiano: 1 . Artes de fazer. Petrópolis, RJ: Vozes, 2011.

ESTEBAN, Maria Teresa; ZACCUR, Edwiges. A pesquisa como eixo de formação docente. In: ESTEBAN, Maria Teresa e ZACCUR, Edwiges (Orgs.). Professora-pesquisadora: uma práxis em construção. Rio de Janeiro: DP\&A, 2002.

FREIRE, Paulo; GUIMARÃES, Sérgio. Dialogando com a própria história. São Paulo: Paz e Terra, 2011.

FREIRE, Paulo. À sombra desta mangueira. São Paulo: Olho d’Água, 2001a. 
Educação como prática da liberdade. Rio de Janeiro: Paz e Terra, 2001b.

UNESP, 2000.

Pedagogia da indignação: cartas pedagógicas e outros escritos. São Paulo: Editora

Pedagogia da autonomia. São Paulo: Paz e terra, 1999.

Educação e mudança. Rio de Janeiro: Paz e Terra, 1981.

GERALDI, João Wanderley. Prefácio. In: MOURA, Edite Marques. Leitura em Bakhtin e Paulo Freire - Palavras e mundos. São Carlos: Pedro e João Editores, 2012.

LARROSA, Jorge. Dar a leer... quizá - notas para uma dialógica de la transmisión. In: YUNES, Eliana e OSWALD, Maria Luiza (Orgs.). A experiência da leitura. São Paulo: Edições Loyola, 2003.

PÉREZ, Carmen Lúcia Vidal. Vozes, palavras, textos: as narrativas autobiográficas na formação de professoras-alfabetizadoras. Tese de Doutoramento. Universidade de São Paulo. Faculdade de Educação, 2002.

PONZIO, Augusto. Procurando uma palavra outra. São Carlos: Pedro \& João Editores, 2010.

SOLIGO, Rosaura \& PRADO, Guilherme do Val Toledo. Leitura e escrita: dois capítulos desta história de ser educador. In: PRADO, Guilherme do Val Toledo \& SOLIGO, Rosaura. Porque escrever é fazer história. São Paulo, Graf. FE, 2005.

SUAREZ, Daniel. Investigação Educativa e Redes de Formação Docente: questões de pesquisa. Palestra proferida na UNIRIO, abril de 2013.

Docentes, narrativa e investigación educativa. La documentación narrativa de las prácticas docentes y la indagación pedagógica del mundo y las experiencias escolares. In: SVERDLICK, Ingrid ... [et.al.]. La investigación educativa: una herramienta de conocimiento y de acción. Buenos Aires: Centro de Publicaciones Educativas y Material Didáctico, 2007.

\footnotetext{
${ }^{i}$ Doutora em Educação (UFF), Professora da rede pública municipal do Rio de Janeiro - SME/RJ

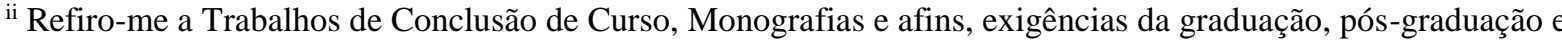
especialização.

iii Utilizarei o feminino da palavra porque nós, professoras, somos maioria na docência.

iv A intenção de aglutinar termos ao longo deste texto deve-se à necessidade de afirmar a estreita relação entre eles e, consequentemente, sua indissociabilidade.
} 